\title{
EDITORIAL
}

\section{Special issue of the workshop on indoor air quality in hot arid climate}

\author{
M. F. Yassin ${ }^{1}$
}

Published online: 27 April 2019

(C) Islamic Azad University (IAU) 2019

\section{Foreward}

Indoor air quality (IAQ) refers to the air quality within and around buildings and structures, especially as it relates to the health and comfort of building occupants. IAQ can be affected by particulates, gases (e.g., volatile organic compounds, carbon monoxide, radon and so on), microbial contaminants (mold, bacteria), or any mass or energy stressor that can induce adverse health conditions. Understanding and controlling common pollutants indoors can help reduce the risk of indoor health concerns and symptoms of occupants.

The workshop entitled "Indoor Air Quality in Hot Arid Climate (IAQHAC) 2017" is the first event on this topic to be held in the Middle East. The IAQHAC workshop is a scientific practicum aimed to support the provision of healthy, comfortable and productive indoor environments in hot arid climates. It will cover a wide range of key research areas with the goal of simultaneously improving indoor environmental quality and enhancing occupants' health and welfare. The IAQHAC also hopes to discuss different subjects on IAQ, i.e., IAQ and impact on regional to global scales; IAQ database and information systems; IAQ management and policy; chemical and physical transformation processes prevalent in indoor spaces; environmental and health impact, resulting from indoor pollution; measurement of indoor air pollutants and process studies; personal exposure to indoor air pollution; sick building syndrome; and current trends to international and regional guidelines and standards. The IAQHAC 2017 is aimed to provide a wide platform for information exchange and knowledge transfer among participants. Finally, I would like to give sincere thanks to the International Journal of Environmental Science and Technology (IJEST) and Editorial Office during the review process of manuscripts.

M. F. Yassin

mohamed_f_yassin@hotmail.com

Environmental Pollution and Climate Program, Environment and Life Sciences Research Center, Kuwait Institute for Scientific Research, Kuwait City, Kuwait 